\title{
TESTE DE METODOLOGIA ALTERNATIVA PARA MENSURAÇÃO DE ESCOAMENTO SUPERFICIAL DE ÁGUA NO SOLO EM AMBIENTES FLORESTAIS
}

\author{
Carlos Augusto Petersen Parchen ${ }^{1}$, Sylvio Péllico Netto ${ }^{2}$, Nivaldo Eduardo Rizzi ${ }^{3}$ \\ ${ }^{1}$ Eng. Agrônomo, Dr., PUCPR, EMATER-PR, Curitiba, PR, Brasil - caparchen @ terra.com.br \\ ${ }^{2}$ Eng. Florestal, Dr., PUCPR, Curitiba, PR, Brasil - sylviopelliconetto@ gmail.com \\ ${ }^{3}$ Eng. Florestal, Dr., Depto. de Engenharia e Tecnologia Florestal, UFPR, Curitiba, PR, Brasil - niva@ufpr.br \\ Recebido para publicação: 04/04/2008 - Aceito para publicação: 06/12/2010
}

\begin{abstract}
Resumo
Medições in situ são de elevada importância na caracterização dos dados necessários para se estudar os parâmetros de água em bacias hidrográficas, cujos conhecimentos gerados, ao serem transformados em práxis tecnológica e metodológica, terão importantes repercussões técnicas, econômicas e sociais. $\mathrm{O}$ presente trabalho teve por objeto testar um sistema alternativo de determinação do escoamento superficial de água no solo, de baixo custo, alta praticidade e portabilidade dos aparelhos utilizados, voltado à instalação e operação em ambiente florestal natural ou reflorestado. Os experimentos foram conduzidos no município de Tijucas do Sul, PR. A área experimental apresentava uma cobertura florestal composta de fragmentos com vegetação primária, fragmentos naturais em estágio avançado de regeneração e reflorestamento com Pinus spp. Calhas coletoras foram utilizadas para a obtenção de dados sob condições de chuva natural, entre março e dezembro de 2006. O conjunto de equipamentos usados, associado aos dados de precipitação, mostrou-se muito eficiente na determinação do escoamento superficial, o que foi demonstrado pela análise de significância de médias (Tukey 5\%). Os experimentos mostraram como a hidrologia de superfície se comporta em função da pluviometria interna e total em uma área de floresta. Pode ser afirmado que a metodologia testada é eficiente e confiável.

Palavras-chave: Infiltração; parâmetros de água; calhas coletoras; floresta.
\end{abstract}

\begin{abstract}
Test of alternative methodology for meauseres of water surface runoff in forest environment. Measurements in situ are of great importance for data characterization in order to evaluate water parameters in hydrological basins, whose generated knowledge, as soon as transformed into technological and methodological praxis, may promote important technical, economic and social repercussions. This work had as its mais objective to improve an alternative system for determination of the surface runoff on the ground, at a low cost, portable and highly workable, in order to be properly installed and operated in natural or in man made forest environment. The experiments had been done in areas of "Tijucas do Sul", Parana State, Brazil. In the experimental area there are fragments with primary vegetation, natural fragments in advanced stage of regeneration and reforestation areas with Pinus spp.. Collecting gutters were used for data collection under natural rain conditions, between March and December of 2006. The set of used equipment, associated with precipitation data, revealed itself as very efficient in determination of the surface water flowoff, which was demonstrated by the statistical comparison of average means (Tukey 5\%); the experiments had shown how this surface hydrological phenomenon holds in relation to internal and total rainfall in a forest area. It can be testified that such methodological test is efficient and trustworthy.

Keywords: Infiltration; water parameters; colleting gutters; forest.
\end{abstract}

\section{INTRODUÇÃO}

Medições in situ são de elevada importância na caracterização dos dados necessários para se estudar os parâmetros de água em bacias hidrográficas, que permitam a tomada de decisão até para remuneração da produção de água e da cobrança pelo seu uso. Exemplo disso é a caracterização do 
movimento da água no solo, em condição de não saturação, tais como infiltração, escoamento da água de chuva, irrigação e movimento de solutos e nutrientes (SILVA; GODINHO, 2002).

No entanto, esses tipos de estudos e pesquisas encontram dificuldades de execução, pois os métodos usuais (padrões) para tais determinações requerem semanas de testes e grande quantidade de água, além de pessoal treinado e equipamentos caros (SILVA; GODINHO, 2002).

Como desvantagem mais crítica desses métodos, tem-se o reduzido número de valores pontuais que se pode estimar e, ainda, acrescido pela complicação devida à variabilidade espacial e temporal das características do solo (SILVA; GODINHO, 2002).

Destaca Oliveira (2003) que essas dificuldades de medições e mensurações envolvendo os processos de precipitação, evaporação, infiltração, escoamento e outros parâmetros hidrológicos, geram complicações e limitações para a utilização de modelos matemáticos. Alerta o autor que nenhuma metodologia substitui as medições de informações capazes de aferir os parâmetros do modelo utilizado. Quanto menor for a disponibilidade de informações, maiores serão as incertezas dos prognósticos, sendo, portanto, objetivo a ser perseguido melhorar as formas de coleta de dados, qualitativa e quantitativamente.

Dentro dessa mesma questão, no que se refere ao comportamento da água precipitada, infiltração e escoamento superficial decorrentes, tem sido destacada também a dificuldade de uso das parcelaspadrão, que exigem isolamento de áreas, por produzirem efeitos de borda, que alteram a realidade e não reproduzem adequadamente o ambiente natural (FRANCO et al., 2002). Além disso, sua implantação em florestas naturais é bastante dificultada e acaba, dessa forma, se tornando invasiva.

Métodos de alta eficiência para determinação de taxas de infiltração e de água de escoamento superficial (PANACHUKI et al., 2006), como os infiltrômetros de aspersão, se mostram ineficazes na aplicação em ambientes florestais, especialmente em medições multipontuais, pela baixa portabilidade e difícil transporte dos itens necessários para sua operação, além do custo elevado.

Considerando-se esse aspecto, é importante o estudo de novas metodologias para a determinação da velocidade de infiltração básica (COELHO et al., 2000).

O método a ser selecionado para determinação do comportamento da água na superfície do solo, em especial para uma adequada determinação das características de infiltração de água no solo e do escoamento superficial, deve representar esses fenômenos de forma análoga ao que ocorre na natureza, pois a taxa de infiltração é influenciada pelas condições de superfície, pelas características do solo, tais como distribuição de tamanho e volume de poros, presença de horizontes estratificados, textura e tipo de argila e pelo teor de umidade do solo (PRUSKI et al., 2002; PANACHUKI et al., 2006).

Destaca Mauro (2003) que, dentro desse enfoque, no Brasil esse campo de estudo encontra-se muito pouco explorado. $\mathrm{O}$ autor exemplifica as seguintes áreas: a da caracterização da zona ripária; a das medições hidrológicas em microbacias experimentais, com o objetivo de desenvolver modelos específicos de previsão do escoamento direto; a de medições isoladas dos componentes de escoamento ao longo das encostas; a das propriedades hidrológicas do solo nas áreas saturadas; e a do aspecto dinâmico da água em zona ripária. Afirma que estudos nesses segmentos são raros e muito necessários.

Como parte de todo esse processo, buscou-se, então, o desenvolvimento de dispositivos e metodologias, realmente simples, para determinação das relações ocorrentes com a água que atinge a superfície do solo e também para estudos de movimento de água em solo não saturado.

Essa metodologia deve ser eficiente e eficaz em ambientes florestais, com uso de instrumentos portáveis, capaz de ser aplicada em muitos pontos, de custo baixo e simplicidade operacional, com baixo consumo de água e pouca aplicação de mão de obra.

Todo conhecimento científico que se obtenha nessa área, possível de ser transformado em práxis tecnológica e metodológica, terá importantes repercussões técnicas, econômicas e sociais, conforme descrito anteriormente.

É neste sentido e com tal intenção que o presente estudo se direcionou, visando contribuir, de forma efetiva, para o estudo do ciclo da água no ambiente florestal.

Este trabalho teve por objeto testar um sistema alternativo de determinação do escoamento superficial de água proveniente de chuva natural, de baixo custo, de alta praticidade e portabilidade e desenvolvido para instalação e operação em ambiente florestal, natural ou reflorestado.

\section{MATERIAL E MÉTODOS}

A área experimental está localizada no município de Tijucas do Sul, Paraná, no Sistema Ecológico VIVAT Floresta, situado geograficamente no Primeiro Planalto Paranaense, entre $25^{\circ} 45^{\prime}$ $26^{\circ} 00^{\prime} \mathrm{S}$ e $49^{\circ} 20^{\prime}-49^{\circ} 05^{\prime} \mathrm{W}$, com altitudes variando entre 800 e $1.350 \mathrm{~m}$ acima do nível do mar. O clima 
local, segundo a classificação de Köppen, é designado como Cfb, definido como subtropical úmido mesotérmico, com verão fresco.

A geologia predominante é de rochas ígneas intrusivas, em especial granitos, apresentando solos de textura média a argilosa, em especial os classificados nas seguintes unidades de maepamento: Argissolos Vermelho-Amarelo Distrófico Típico; Associação de Cambissolo Háplico Distrófico Típico com Argissolo Vermelho-Amarelo Distrófico Câmbico; Associação Cambissolo Háplico Distrófico Típico com Neossolo Litólico Distrófico Típico, com eventuais afloramentos de rochas. A topossequência da área é mostrada na figura 1.

Os dados pluviométricos necessários aos experimentos foram obtidos de duas maneiras: a primeira através de uma Plataforma de Coleta de Dados Automática (PCD) do Instituto Nacional de Pesquisas Espaciais (INPE), situada próximo ao centro geográfico da área experimental, e a segunda através de pluviômetros instalados ao lado de cada uma das repetições do experimento.

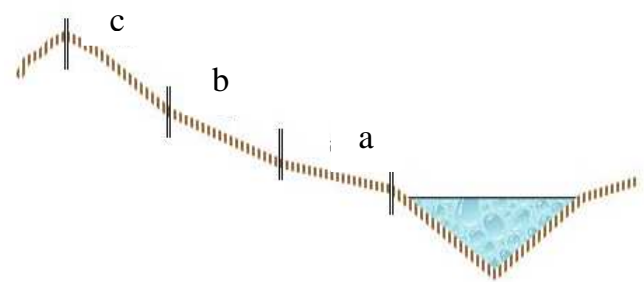

Figura 1. Topossequência da área do experimento: a) Argissolos Vermelho-Amarelo Distrófico Típico; b) Associação de Cambissolo Háplico Distrófico Típico com Argissolo Vermelho-Amarelo Distrófico Câmbico; c) Associação Cambissolo Háplico Distrófico Típico com Neossolo Litólico Distrófico Típico, com eventuais afloramentos de rochas.

Figure 1. Toposequence of the experimental área: a) Tipical red-yellow argisoil distrofic; b) Association of tipical cambisoil haplic distrofic with red-yellow argisoil distrofic cambic; c) Association of tipical cambisoil haplic distrofic with tipical neosoil litolic distrofic, with eventual rock showup.

A vegetação natural da área é da formação Floresta Ombrófila Mista. Na área experimental existem fragmentos com vegetação primária (floresta nativa), fragmentos naturais em estágio avançado de regeneração e também reflorestamento com Pinus spp., com 25 anos de idade.

Tendo em vista os objetivos deste trabalho, já citados na introdução, as calhas coletoras e seus periféricos foram projetados para servir em condições de difícil instalação de outros equipamentos, com praticidade, facilidade de transporte, baixo consumo de água, pequena aplicação de mão de obra e baixo custo. A metodologia foi testada até se conseguir um procedimento prático, eficiente e eficaz de instalação e operação.

Basicamente, a calha coletora é constituída de uma estrutura retangular confeccionada em chapa metálica galvanizada de $1,1 \mathrm{~mm}$ de espessura, retângulo este com as dimensões internas de $0,98 \mathrm{~m}$ de comprimento, $0,27 \mathrm{~m}$ de largura e $0,11 \mathrm{~m}$ de altura, acoplado, de forma comunicante, a uma estrutura triangular vedadas nas partes superior e inferior e no vértice, para evitar que a água de precipitação fosse captada diretamente (Figura 2).

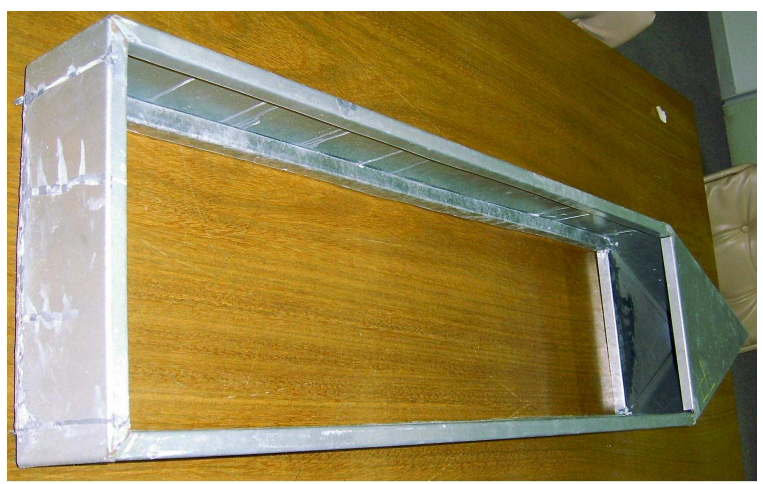

Figura 2. Estrutura retangular acoplada à estrutura triangular.

Figure 2. Retangular structure connected to a triangular structure.

FLORESTA, Curitiba, PR, v. 41, n. 3, p. 629-640, jul./set. 2011. 
A estrutura em forma de triângulo foi concebida para receber e concentrar a água captada na área delimitada pelo retângulo coletor e dirigi-la para dois canos metálicos, com diâmetro externo de $1 / 2$ polegada, localizados junto à base do vértice dessa estrutura. As figuras 3 e 4 mostram a estrutura descrita.

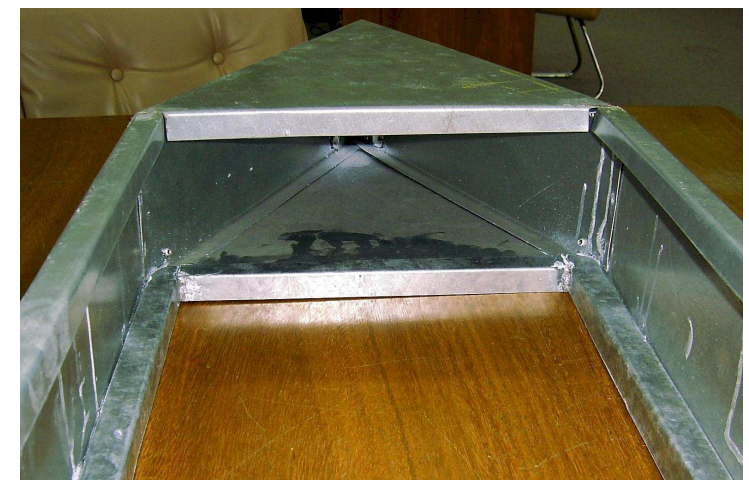

Figura 3. Acoplamento da estrutura triangular fechada à estrutura retangular.

Figure 3. Connection of the closed triangular structure to a retangular structure.

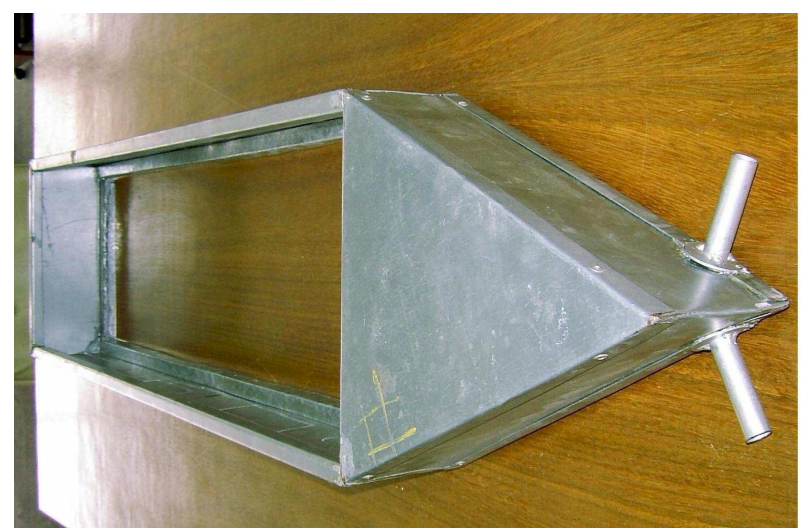

Figura 4. Estrutura triangular fechada e canos de saída de água.

Figure 4. Closed triangular structure with water drain pipes.

Para dar suficiente rigidez à estrutura retangular, as bordas superior e inferior foram dobradas com $1 \mathrm{~cm}$ de largura, em forma de $\mathrm{L}$ na base e em forma de C (c retangular) no topo, o que resultou em aumento de dois centímetros no comprimento e na largura da referida estrutura. Em toda a base da calha foi soldada uma lâmina vertical de 0,02 m (Figura 5), que tem a função de penetrar o solo e evitar o escape da água de escoamento por baixo da calha coletora.

Na ponta da estrutura triangular, na sua parte inferior, onde a água captada é concentrada, foram colocados dois canos metálicos, um de cada lado do triângulo, com medida externa de 1/2 polegada (Figura 6), onde eram encaixadas duas mangueiras plásticas de polietileno (PVC flexível), com a função de conduzir a água captada até o ponto de coleta ou de medição.

Com a técnica construtiva adotada, a estrutura como um todo ficou bem rígida e resistente, sem apresentar deformações no transporte e na instalação, e com peso reduzido $(9,3 \mathrm{~kg})$, o que facilita o transporte em condições de floresta e trilhas no interior dela.

Para evitar que folhas ou materiais grosseiros fossem transportados para dentro dos tubos, causando obstruções ao fluxo de água, foram colocadas na ponta da estrutura triangular, duas esponjas de lã de aço, tipo "palha de aço", abertas e desfiadas, com a finalidade de filtrar a água do escoamento superficial.

Para cada mesa coletora utilizaram-se dois tubos flexíveis (mangueiras), que conduziam a água coletada até os tambores de armazenamento. Foi utilizado tubo flexível com diâmetro interno de $1 / 2$ 
polegada de polietileno e de cor preta, por ser de baixo custo, ser à prova de radiação solar e resistir bem em ambientes abertos.

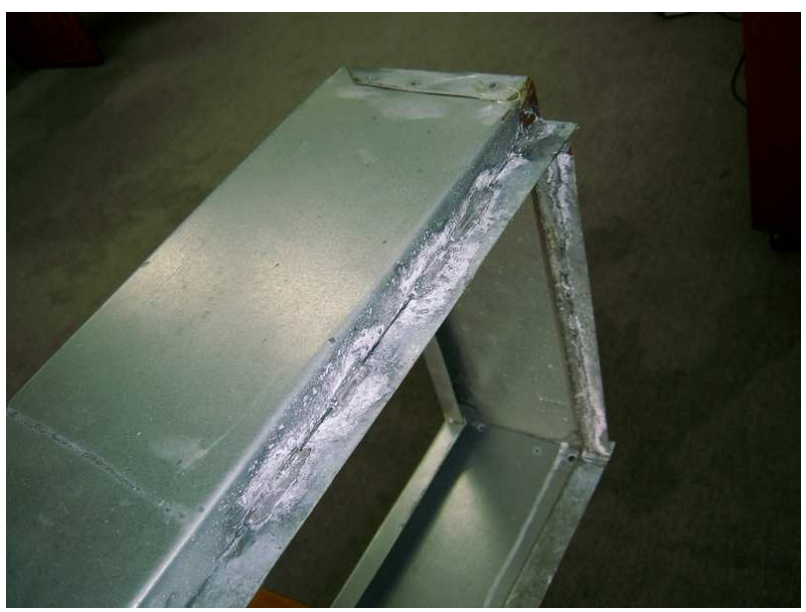

Figura 5. Detalhe da lâmina de penetração no solo e vedação de escape do escoamento superficial. Figure 5. Detail of blade penetration into the soil and seal exahaust runoff.

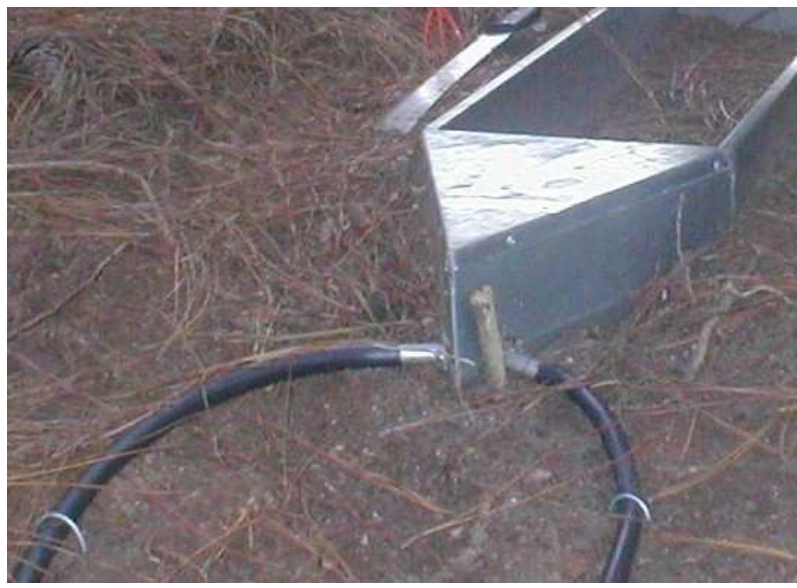

Figura 6. Encaixe das mangueiras flexíveis nos tubos metálicos.

Figure 6. Connection of the water drain pipes with the flexible rubber hoses.

Cada mesa coletora estocava a água coletada do escoamento superficial em um tambor. Foram utilizados tambores plásticos, tipo "bombonas", com capacidade de 50 litros, determinada em função do potencial de captação de água da mesa coletora. Os tambores utilizados eram fechados, com duas tampas plásticas rosqueáveis, estrutura rígida e duas alças para transporte.

Ao lado de cada unidade (calha coletora) foi colocado um pluviômetro, fixado em uma estaca de madeira de dimensões de $1,80 \mathrm{~m}$ de altura, $0,11 \mathrm{~m}$ de largura e $0,02 \mathrm{~m}$ de espessura. Foram utilizados pluviômetros plásticos de leitura direta, da marca J. Prolab, fabricados em São José dos Pinhais (PR), com capacidade de registro de precipitações de até $130 \mathrm{~mm}$. As coletas de precipitações eram aferidas com o auxílio de proveta graduada de $100 \mathrm{ml}$, com marcação (escala) de $0,5 \mathrm{ml}$.

Foi utilizada proveta de laboratório para medir o volume de água armazenada nos tambores. Esse equipamento tinha uma capacidade de $2.000 \mathrm{ml}$ e marcação de $10 \mathrm{em} 10 \mathrm{ml}$, sendo dotado de uma base plástica bastante grande, o que facilitava sua colocação sobre o solo e o aprisionamento com os pés e um tamanho da "boca" bastante adequado, permitindo, assim, transferir a água do tambor para a proveta sem 
risco de acidente. Isso permitia, de maneira muito prática e eficiente, que uma única pessoa pudesse fazer as leituras (medições) do experimento.

$\mathrm{Na}$ instalação das calhas coletoras, tomou-se o cuidado de evitar locais com ocorrência de raízes superficiais de árvores e buscaram-se locais onde o solo era o mais regular possível em termos de nivelamento transversal e horizontal (desconsiderada a declividade), pois a calha coletora exige um contato uniforme com o solo em todo o seu perímetro. Escolhido o local, colocava-se a calha sobre o solo, com o vértice apontando para o sentido da declividade dominante, verificando-se seu contato inicial com o solo.

Quando a camada de serapilheira era muito espessa, como no caso do reflorestamento com pínus, ela era cuidadosamente removida para o lado, no mesmo alinhamento (sentido) em que antes se encontrava, para facilitar a reposição após a fixação da calha. Estando a calha em contato com o solo, era observado se a borda inferior, em todo o seu perímetro, estava em contato com o solo e se não existiam torrões ou pequenas elevações que estivessem impedindo o correto nivelamento das bordas. Quando existiam, eram removidos com o auxílio de uma faca ou enxada, cuidadosamente manejada para evitar revolvimento do solo. Obtido o nivelamento desejado, pressionava-se a calha coletora com as mãos, utilizando-se o peso do corpo, até que a borda inferior, na parte dobrada em "L" ficasse perfeitamente nivelada com a superfície do solo e a lâmina vertical completamente cravada nele. Se alguma raiz impedia o nivelamento da calha, era cortada, passando-se uma cortadeira reta rente a parede externa da calha coletora, num movimento de cima para baixo.

Para impedir que a calha viesse a se deslocar para frente ou lados, três estacas de madeira ( $0,20 \mathrm{~m}$ de comprimento), cortadas no próprio mato, eram utilizadas da seguinte forma: duas estacas eram fixadas no solo junto ao vértice da calha, encaixadas no encontro dos tubos metálicos com as chapas metálicas da estrutura triangular, e uma estaca era fixada no centro da parte externa da borda traseira, pressionando fortemente a estrutura metálica. Isso garantia que a calha coletora não sofreria deslocamento em qualquer sentido. Nas calhas coletoras em que a serapilheira fora removida, esta era recolocada na sua posição original, cuidando-se para que as bordas inferiores da calha ficassem perfeitamente recobertas. Cuidava-se, de forma especial, para que não houvesse pisoteio na área interna da calha coletora, para manter a condição natural do solo e não causar alteração na taxa de infiltração. Com o objetivo de remover qualquer selamento de solo que pudesse ter se formado durante a instalação, escarificava-se toda a área interna da calha com um ancinho de jardinagem, tomando-se o cuidado de mobilizar apenas a camada bem superficial do solo.

Estando a calha coletora fixada, media-se a distância do vértice desta até o local onde eram fixados os tambores plásticos e cortavam-se dois pedaços de mangueira, com cerca de $10 \%$ a mais do que a medida aferida, para compensar curvaturas na mangueira devido a irregularidade do terreno, desvios impostos pela vegetação, bem como para atender a necessidade de a mangueira alcançar o fundo do tambor. Logo após a saída das mangueiras dos tubos, estas eram fixadas no solo com o auxílio de dois ganchos, feitos com arame grosso. As mangueiras eram então esticadas, na linha mais reta possível, até o local dos tambores de armazenamento de água. Em razão da necessidade de manter a mangueira rente ao solo, ela era fixada a arbustos com fitas e/ou ganchos feitos de arame. Para evitar que as mangueiras "estocassem" água em razão de não trabalharem em seção plena (afogado ou seção molhada total), tomou-se cuidado para que o ponto mais distante da mesa coletora estivesse em cota inferior a todos os pontos anteriores, de modo a garantir o escoamento de toda a água captada.

\section{Procedimentos de coleta de dados}

A determinação do volume da água do escoamento superficial captada pelos tambores era feita de uma forma bastante simples. Para maior agilidade, era realizada por duas pessoas, podendo, no entanto, ser realizada por apenas uma. Para tal, as duas mangueiras eram desconectadas do tambor, cuidando-se para que toda a água escoasse da mangueira para dentro dele. A seguir transferia-se a água do tambor para a proveta. A leitura era realizada diretamente na escala da proveta e, quando o volume armazenado excedia a $2.000 \mathrm{ml}$ (capacidade da proveta), fazia-se a somatória de várias leituras.

\section{Delineamento}

Foram selecionados 5 locais, que se constituíram nos tratamentos deste experimento, utilizandose os seguintes critérios:

- dois tipos de vegetação: floresta nativa e reflorestamento com pínus; 
- dois tipos de relação solo/paisagem, ou seja, duas diferentes posições na topossequência em cada tipo de vegetação;

- uma área descoberta (sem dossel), de solo nu;

Cuidou-se para que os locais selecionados estivessem próximos de uma trilha, para facilitar o transporte manual dos equipamentos e ferramentas e as medições, mesmo sob condições de clima adversas.

Selecionada previamente uma região, com o auxílio de mapas de solo, de uso do solo e de imagens de satélite, escolhia-se, aleatoriamente, uma área para instalação do experimento. Os tratamentos ficaram assim localizados e identificados pela vegetação e relevo:

Tratamento 1: Floresta Ombrófila Mista, relevo plano, posição a na topossequência, declividade de 5\%; Solo: Argissolo Vermelho-Amarelo Distrófico Típico.

Tratamento 2: Floresta Ombrófila Mista, relevo de meia encosta, posição b na topossequência, declividade de 26\%; Solo: Associação Cambissolo Háplico Distrófico Típico com Neossolo Litólico Distrófico Típico.

Tratamento3: Área aberta (sem dossel florestal), relevo suave ondulado, posição a na topossequência, declividade de 9\%; Solo: Argissolo Vermelho-Amarelo Distrófico Típico.

Tratamento 4: Povoamento com pínus, relevo ondulado, posição b na topossequência, declividade de 18\%; Solo: Associação Cambissolo Háplico Distrófico Típico com Argissolo VermelhoAmarelo Distrófico Câmbico.

Tratamento 5: Povoamento com pínus, relevo forte ondulado, posição c na topossequência Solo: Associação Cambissolo Háplico Distrófico Típico com Argissolo Vermelho-Amarelo Distrófico Câmbico.

Cada tratamento era constituído de 4 calhas coletoras, instaladas próximas, na área homogênea escolhida, entre as árvores, na mesma situação de solo/topografia (paisagem). Cada mesa coletora e seus periféricos era uma repetição do experimento, constituindo-se essa unidade, além da mesa coletora, do pluviômetro colocado na estaca fixadora, dos tubos de condução de água e do tambor de coleta e armazenamento de água.

Foram realizadas 24 leituras entre março e dezembro de 2006, sendo que muitos eventos (leituras) eram acumulativos, ou seja, representaram chuvas intermitentes ao longo de períodos de até 72 horas. As precipitações desse ano foram bastante atípicas, com chuvas espaçadas e de baixa intensidade.

\section{Custos das unidades}

Apresenta-se a seguir os custos das unidades experimentais, não computados mão de obra de instalação a campo nem os custos das ferramentas necessárias para a sua instalação, porque esses componentes de custos foram disponibilizados pela estrutura do VIVAT Floresta. Estão apresentados apenas os custos de desembolso direto, com base nos preços de agosto de 2005.

- Confecção das calhas (unidade)

$\mathrm{R} \$ 60,00$

- Tubos flexíveis - 25 m por unidade.

$\mathrm{R} \$ 8,75$

- Tambor plástico (unidade)

$\mathrm{R} \$ 10,50$

- Palha de aço (unidade)

$\mathrm{R} \$ \quad 0,85$

- Pluviômetro (unidade)

$\mathrm{R} \$ 7,50$

- Arame grosso - 2,0 m por unidade

$\mathrm{R} \$ 1,20$

- Fitilho de amarrio - 5,0 m por unidade

$\mathrm{R} \$ \quad 0,20$

- Estacas fixadoras (unidade).

$\mathrm{R} \$ 3,00$

- Valor total por repetição

$\mathrm{R} \$ 92,00$

$\mathrm{Na}$ instalação das calhas ou mesas coletoras e todos os seus periféricos, trabalhando-se em três pessoas, utilizou-se um tempo médio de duas horas para instalar as quatro repetições de cada bloco, o que significa uma aplicação média de 1,5 horas/homem por unidade (repetição) instalada. Esse tempo não incluiu o transporte de todo o material para o local de instalação selecionado. Incluindo-se o transporte dos materiais da sede do VIVAT Floresta até os locais na floresta e no reflorestamento, as 20 unidades (repetições) foram instaladas em dois dias, num total de 16 horas de trabalho, o que significou uma equivalência de 2 horas/homem de trabalho por repetição (unidade) instalada. A equipe de trabalho era constituída do pesquisador e de dois trabalhadores operacionais. 


\section{RESULTADOS E DISCUSSÃO}

Apresenta-se a seguir os dados médios das determinações realizadas, sendo utilizadas as seguintes convenções:

- $\mathrm{T}$ = água de escoamento superficial coletada em cada repetição captada nos tambores.

- $\quad \mathrm{P}=$ água de precipitação coletada em cada repetição, calculada a partir do dados dos pluviômetros.

- $\quad \mathrm{PCD}=$ precipitação medida na plataforma automática de coleta de dados (INPE) da área do experimento.

Os dados estão apresentados em ordem crescente de precipitações ocorridas e mostradas na tabela 1. A figura 7 representa a variação da pluviosidade durante o período de execução do experimento.

Tabela 1. Dados médios dos tratamentos.

Table 1. Treatment average data.

\begin{tabular}{|c|c|c|c|c|c|c|c|c|c|c|}
\hline \multirow{3}{*}{$\begin{array}{l}\text { Preci- } \\
\text { pita- } \\
\text { ção } \\
\text { (PCD) } \\
\text { mm }\end{array}$} & \multicolumn{2}{|c|}{ Tratamento 1} & \multicolumn{2}{|c|}{ Tratamento 2} & \multicolumn{2}{|c|}{ Tratamento 3} & \multicolumn{2}{|c|}{ Tratamento 4} & \multicolumn{2}{|c|}{ Tratamento 5} \\
\hline & $\begin{array}{l}\text { Escoa- } \\
\text { mento } \\
(\mathrm{T})\end{array}$ & $\begin{array}{c}\text { Água } \\
\text { captada } \\
\text { nas calhas } \\
\text { (P) }\end{array}$ & $\begin{array}{l}\text { Escoa- } \\
\text { mento } \\
(\mathrm{T})\end{array}$ & $\begin{array}{c}\text { Água } \\
\text { captada } \\
\text { nas calhas } \\
\text { (P) }\end{array}$ & $\begin{array}{l}\text { Escoa- } \\
\text { mento } \\
(\mathrm{T})\end{array}$ & $\begin{array}{c}\text { Água } \\
\text { captada } \\
\text { nas calhas } \\
\text { (P) }\end{array}$ & $\begin{array}{l}\text { Escoa- } \\
\text { mento } \\
(\mathrm{T})\end{array}$ & $\begin{array}{c}\text { Água } \\
\text { captada } \\
\text { nas calhas } \\
\text { (P) }\end{array}$ & $\begin{array}{l}\text { Escoa- } \\
\text { mento } \\
(\mathrm{T})\end{array}$ & $\begin{array}{c}\text { Água } \\
\text { captada } \\
\text { nas calhas } \\
\text { (P) }\end{array}$ \\
\hline & $\mathbf{m l}$ & ml & ml & ml & $\mathbf{m l}$ & ml & ml & ml & ml & ml \\
\hline 1,3 & 0,0 & 232,40 & 0,0 & 199,20 & 0,0 & 370,44 & 0,0 & 251,37 & 0,0 & 257,99 \\
\hline 2 & 0,0 & 385,12 & 0,0 & 325,36 & 0,0 & 562,28 & 0,0 & 410,13 & 0,0 & 423,36 \\
\hline 3,5 & 0,0 & 717,12 & 0,0 & 637,44 & 0,0 & 886,41 & 0,0 & 754,11 & 0,0 & 773,96 \\
\hline 5 & 135,0 & 1115,52 & 96,5 & 1002,64 & 145,0 & 1276,70 & 10,0 & 1117,94 & 45,0 & 1137,78 \\
\hline 5,55 & 141,5 & 1221,76 & 84,0 & 1188,56 & 155,0 & 1442,07 & 0,0 & 1263,47 & 0,0 & 1223,78 \\
\hline 6 & 26,5 & 1328,00 & 27,5 & 1314,72 & 315,0 & 1574,37 & 51,5 & 2110,19 & 52,5 & 2070,50 \\
\hline 9,45 & 167,5 & 2257,60 & 75,0 & 2231,04 & 475,0 & 2632,77 & 55,0 & 2176,34 & 125,0 & 2229,26 \\
\hline 9,75 & 77,5 & 2310,72 & 139,0 & 2317,36 & 545,0 & 2639,39 & 38,5 & 2262,33 & 130,0 & 2295,41 \\
\hline 11,3 & 146,5 & 2735,68 & 126,5 & 2675,92 & 495,0 & 2811,38 & 42,5 & 2626,16 & 137,5 & 2698,92 \\
\hline 12,5 & 252,5 & 3087,60 & 145,5 & 2988,00 & 470,0 & 3188,43 & 65,0 & 2937,06 & 93,5 & 3009,83 \\
\hline 14,2 & 145,0 & 3685,20 & 143,5 & 3240,32 & 521,5 & 3386,88 & - & - & - & - \\
\hline 16,3 & 220,0 & 4123,44 & 130,0 & 3904,32 & 646,5 & 4544,51 & 88,5 & 3883,01 & 212,5 & 4035,15 \\
\hline 20 & 940,0 & 5013,20 & 1197,5 & 5132,72 & 2555,0 & 5662,44 & 1487,5 & 4802,49 & 1128,5 & 4848,80 \\
\hline 23,9 & 1542,5 & 5962,72 & 1360,0 & 6075,60 & 2385,0 & 6284,25 & 1495,0 & 5735,21 & 1127,5 & 5669,06 \\
\hline 29,5 & 1315,0 & 7224,32 & 1308,5 & 7609,44 & 2447,5 & 7309,58 & 1412,5 & 7250,04 & 871,5 & 7230,20 \\
\hline 30,3 & 1577,5 & 7496,56 & 1373,5 & 7682,48 & 2735,0 & 7825,55 & 1713,5 & 7514,64 & 1667,5 & 7600,64 \\
\hline 30,5 & 1945,0 & 12184,40 & 1808,5 & 12715,60 & 3505,0 & 9227,93 & 2640,0 & 12469,28 & 2253,5 & 12370,05 \\
\hline 31 & 1462,5 & 7669,20 & 1307,5 & 7569,60 & 3406,5 & 8123,22 & 1630,0 & 7574,18 & 1860,0 & 7845,39 \\
\hline 32 & 1775,0 & 7748,88 & 2490,0 & 8100,80 & 2740,5 & 8586,27 & 1698,5 & 7653,56 & 1223,5 & 7719,71 \\
\hline 35,2 & 1632,5 & 8585,52 & 1271,5 & 8094,16 & 2683,5 & 9565,29 & 2056,5 & 8215,83 & 2392,5 & 8599,50 \\
\hline 39,3 & 1612,5 & 10192,40 & 1753,5 & 11122,00 & 3345,0 & 12224,52 & 2452,5 & 10451,70 & 2602,5 & 10650,15 \\
\hline 55,3 & 2457,5 & 13439,36 & 2212,5 & 13625,28 & 4132,5 & 13613,67 & 2701,5 & 14010,57 & 2185,0 & 14050,26 \\
\hline 57 & 2405,0 & 13857,68 & 2328,5 & 14110,00 & 7452,5 & 14685,30 & 2077,5 & 14089,95 & 1962,5 & 14334,71 \\
\hline 62 & 2555,0 & 15238,80 & 2493,5 & 15438,00 & 4915,0 & 16127,37 & 2733,5 & 15737,09 & 2482,5 & 15876,00 \\
\hline
\end{tabular}

Nesta análise, apresenta-se inicialmente a distribuição de todos os volumes de água de escoamento superficial captados em cada calha coletora, relacionando-os com a precipitação efetivamente ocorrida, mensurada pela PCD, sendo posteriormente apresentada a análise de significância, avaliada pelo teste de Tukey $(5 \%)$.

As médias dos dados obtidos com a medição da água de escoamento superficial foram testadas, por constituírem a medição direta (primária) mais importante para o funcionamento das calhas coletoras, pois os demais dados foram obtidos a partir de cálculos que utilizam esses dados. As precipitações obtidas através dos pluviômetros constituem outro dado de medição direta (primária) de cada unidade experimental.

Na tabela 2 está apresentado o volume médio de água de escoamento por tambor e por tratamento e a análise de significância (Tukey 5\%). 


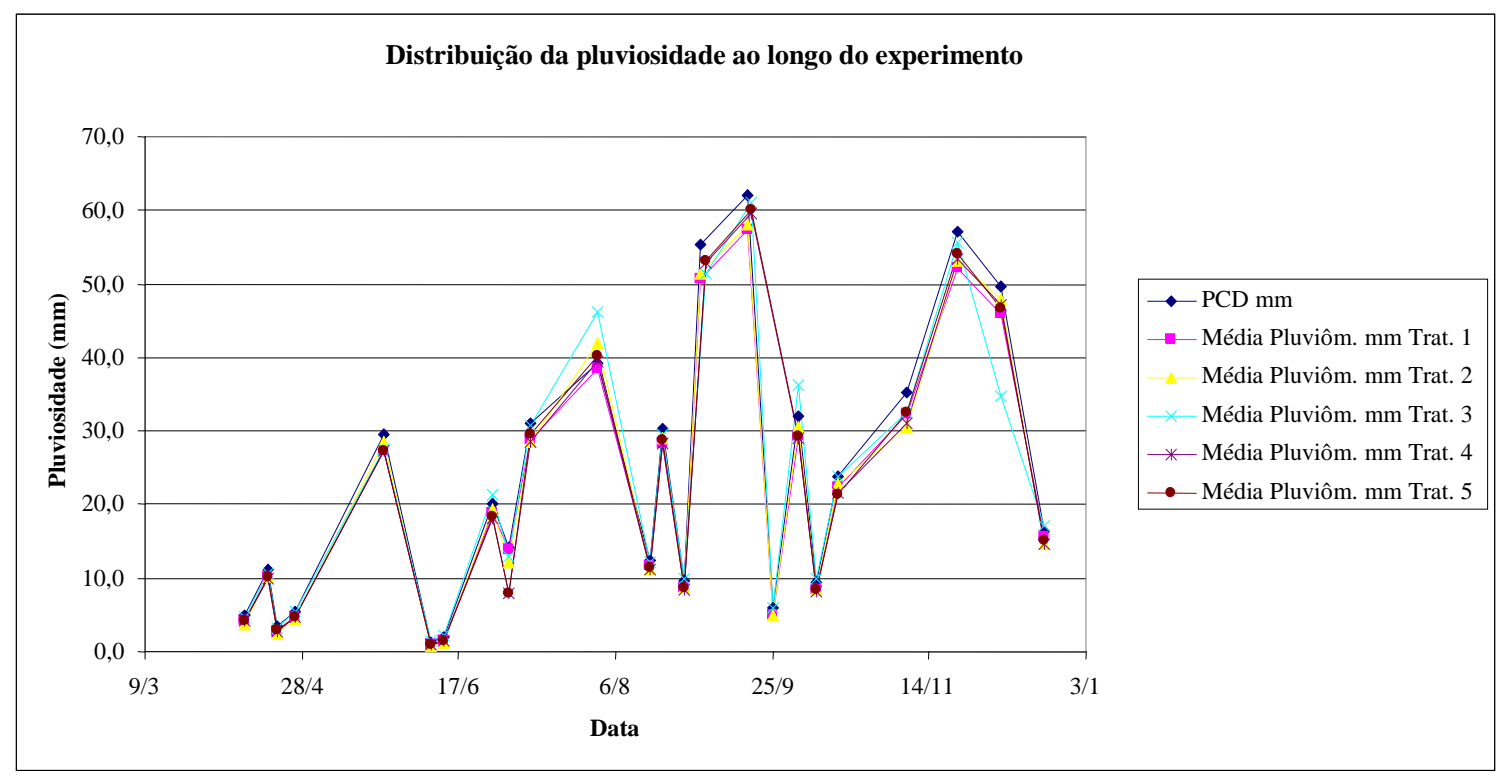

Figura 7. Distribuição da pluviosidade ao longo do período experimental.

Figure 7. Pluviosity distribution along the experimental period.

Tabela 2. Volume médio de água de escoamento por tambor e por tratamento.

Table 2. Average volume of water runoff per drum and per treatment.

\begin{tabular}{lccccc}
\hline & Trat. 1 $(\mathbf{m l})$ & Trat. 2 $(\mathbf{m l})$ & Trat. 3 $(\mathbf{m l})$ & Trat. 4 $(\mathbf{m l})$ & Trat. 5 $(\mathbf{m l})$ \\
\hline Tambor 1 & 891,4 & 863,92 & 1880,4 & 967 & 907,2 \\
Tambor 2 & 870,44 & 870,9 & 1805,84 & 940 & 927,6 \\
Tambor 3 & 912,2 & 894,22 & 1801,2 & 947,8 & 886,4 \\
Tambor 4 & 931,04 & 874,72 & 1883,8 & 1057,2 & 887,4 \\
Total & 3605,08 & 3503,76 & 7371,24 & 3912 & 3608,6 \\
Média & 901,27 & 875,94 & 1842,81 & 978 & 902,15 \\
Origem de variação & gl & SQ & MQ & Fcalc & Ftab \\
Entre os tratamentos & 4 & 2781967 & 695491,80 & 559,71 & 3,06 \\
Dentro dos tratamentos & 15 & 18639,02 & 1242,60 & & \\
\hline Total & 19 & 2800606 & & & \\
\hline Comparações & DEM & & Tukey 5\% & não significante \\
\hline T1 T2 & 0,19 & & 4,23 & significante \\
T1 T3 & 6,94 & & 4,23 & não significante \\
T1 T4 & 0,57 & & 4,23 & não significante \\
T1 T5 & 0,01 & & 4,23 & significante \\
T2 T3 & 7,12 & & 4,23 & não significante \\
T2 T4 & 0,75 & 4,23 & não significante \\
T2 T5 & 0,19 & 4,23 & significante \\
T3 T4 & 6,37 & 4,23 & significante \\
T3 T5 & 6,93 & 4,23 & não significante \\
T4 T5 & 0,56 & 4,23 &
\end{tabular}

Fica evidenciado que a metodologia utilizada tem sensibilidade suficiente para mensurar as variações ocorridas, nas condições em que este estudo foi realizado, sendo que os dados obtidos indicam consistência de resultados, o que está de acordo com o apresentado por diversos autores (COSTA et al., 1999; FABIAN; OTTONI FILHO, 2000; PEREIRA, 2000; OLIVEIRA et al., 2000; FRANCO et al., 2002; CASSOL et al., 2004; BERTOL, 2003; PANACHUKI et al., 2006). Portanto, as calhas coletoras 
de pequeno porte apresentam viabilidade de aplicação nos estudo dos fenômenos pontuais de hidrologia de superfície.

$\mathrm{O}$ tratamento 3 (testemunha) propiciou maior escoamento superficial, diferindo significativamente dos demais. Os resultados refletem o efeito da ausência de cobertura vegetal (viva e morta) nesse tratamento. Os demais tratamentos não diferiram entre si, refletindo efeitos protetores muito semelhantes entre as copas das árvores (dossel) e a serapilheira, na redução do escoamento superficial e no aumento da infiltração de água no solo.

A tabela 3 mostra a percentagem máxima e média de escoamento superficial ocorrida em cada tratamento. Esse percentual é calculado sobre a lâmina precipitada diretamente sobre a calha coletora, medida pelos pluviômetros em cada tratamento e repetição. A coluna de pluviometria mostra a média das precipitações ocorridas em cada tratamento, durante todo o transcorrer do estudo.

Tabela 3. Escoamento superficial em porcentagem em cada tratamento.

Table 3. Percentage of runoff per treatment.

\begin{tabular}{lccc}
\hline Tratamento & Pluviometria $(\mathbf{m m})$ & \% média escoamento & \% máxima escoamento \\
\hline 1 & 20,8 & 11,5 & 25,9 \\
2 & 21,0 & 10,8 & 30,7 \\
3 & 21,9 & 22,9 & 50,7 \\
4 & 20,5 & 11,1 & 31,0 \\
5 & 20,7 & 10,5 & 27,8 \\
\hline Média & 20,9 & 13,4 & 33,2 \\
\hline
\end{tabular}

Evidencia-se que no tratamento 3, com solo desprotegido de vegetação rasteira e sem dossel para interceptação e amortecimento da pluviosidade, o escoamento médio foi o dobro dos demais tratamentos, sendo que o escoamento máximo superou aos demais tratamentos, com valores entre $63 \%$ e $95 \%$ maiores.

O máximo escoamento observado no tratamento 3 , que foi de $50,7 \%$, representou uma perda equivalente à metade de uma precipitação ocorrida, que foi de $55,5 \mathrm{~mm}$, observada no dia 23 de novembro de 2006.

Os dados observados estão coerentes com o tipo de cobertura vegetal (dossel) e com a cobertura morta (serapilheira) e mostram que os equipamentos utilizados têm sensibilidade para as situações apresentadas neste estudo. Todos os dados analisados mostram consistência com as precipitações ocorridas e estão de acordo com dados apresentados em estudos em condições similares, por autores como Mendes et al. (1992), Borges et al. (2005) e outros.

\section{CONCLUSÕES}

- O conjunto da calha coletora, mangueira e tambor, associado aos dados de precipitação, mostrou-se muito eficiente na determinação do escoamento superficial, o que foi demonstrado pela análise de significância de médias (Tukey 5\%).

- Pode ser afirmado que a metodologia proposta, para as condições experimentais adotadas, é eficiente e confiável.

- A aplicação realizada e o embasamento teórico obtido na revisão bibliográfica permitem também afirmar que o equipamento e a metodologia de aplicação podem ser utilizados em estudos similares, em ambientes florestais diversos, e mesmo em áreas de agropecuária, destacando-se, ainda, como fatores positivos, a portabilidade, a facilidade de instalação, a facilidade de obtenção/aquisição de dados, a durabilidade e o baixo custo por unidade.

- A análise dos parâmetros de utilização de simuladores de chuva e o desempenho das calhas coletoras sob condições de chuva natural indicam, ainda, a possibilidade de aplicação da metodologia desenvolvida neste estudo como coletores de infiltrômetros de aspersão, ou seja, sob condições de chuva simulada, o que aumenta o leque de possibilidades de utilização dos equipamentos desenvolvidos ou aplicados. É importante destacar que, com aumento significativo do custo por unidade, é possível automatizar toda a coleta de dados dos equipamentos com a aplicação de pluviógrafos em substituição aos pluviômetros e com a colocação de um "flume" de registro automático de vazão (acoplado a registrador de dados - datalog) em substituição ao tambor coletor de água de escoamento. 


\section{REFERÊNCIAS}

BERTOL, O. J. Contaminação da água de escoamento superficial e da água percolada pelo efeito de adubação mineral e adubação orgânica em sistema de semeadura direta. 209 p. Tese (Doutorado em Engenharia Florestal) - Universidade Federal do Paraná, Curitiba, 2003.

BORGES, M. J.; PISSARA, T. C.; VALERI, S. V.; OKUMURA, E. M. Reflorestamento compensatório com vistas à retenção de água no solo da bacia hidrográfica do Córrego Palmital, Jaboticabal, SP. Scientia Florestalis, n. 69, p. 93 - 103, dez. 2005.

CASSOL, E. A.; CANTALICE, J. R. B.; REICHERT, J. M.; MONDARDO, A. Escoamento superficial e desagregação do solo em entressulcos em solo franco-argilo-arenoso com resíduos vegetais. Pesquisa Agropecuária Brasileira, Brasília, v. 39, n. 7, p. 685 - 690, jul. 2004.

COELHO, R. D.; MIRANDA, J. H.; DUARTE, S. N. Infiltração da água no solo: parte I - infiltrômetro de anéis versus infiltrômetro de aspersores. Revista Brasileira de Engenharia Agrícola e Ambiental, Campina Grande, v. 4, n. 2, p. 137 - 141, 2000.

COSTA, E. L.; SILVA, A. M.; COLOMBO, A.; ABREU, A. R. Infiltração de água em solo, determinada por simulador de chuvas e pelo método dos anéis. Revista Brasileira de Engenharia Agrícola e Ambiental, Campina Grande, PB. v. 3, n. 2, p. 131 - 134, 1999.

FABIAN, A. J.; OTTONI FILHO, T. B. Determinação de capacidade de campo in situ ou através de equações de regressão. Pesquisa Agropecuária Brasileira, Brasília. v. 35, n. 5 p. 1029 - 1036, 2000.

FRANCO, F. S.; COUTO, L.; CARVALHO, A. F.; JUCKSCH, I.; FERNANDES FILHO, E. I.; SILVA, E.; MEIRA NETO, J. A. Quantificação de erosão em sistemas agroflorestais e convencionais na Zona da Mata de Minas Gerais. Árvore, Viçosa-MG, v. 26, n. 6, p. 751 - 760, 2002.

MAURO, F. Vazão e qualidade da água em manancial degradado do cinturão verde de Ilha Solteira, SP. 80 f. Dissertação (Mestrado em Recursos Hídricos, Engenharia Civil) - Faculdade de Engenharia de Ilha Solteira-UNESP. Ilha Solteira, SP. 2003.

MENDES, M. E. G.; VILlaGRA, M. M.; SOUZA, M. D.; BACCHI, O. O. S.; REICHARDT, K. Relações hídricas em seringal no município de Piracicaba. Scientia Agricola, Piracicaba-SP, v. 49, n. 1, p. $103-109,1992$.

OLIVEIRA, G. C. Gestão de Recursos Hídricos: os fatores que influenciam no planejamento. $91 \mathrm{f}$. Dissertação (Mestrado) - UNITAU, Departamento de Economia, Universidade de Taubaté. Taubaté, 2003.

OLIVEIRA, L. F.; MARTINEZ, M. A.; PRUSKI, F. F.; RUIZ, H. A.; LIMA, L. A. Transporte de solutos no solo e no escoamento superficial: I - desenvolvimento do modelo e simulação do movimento de água e escoamento superficial. Revista Brasileira de Engenharia Agrícola e Ambiental, Campina Grande, v. 4, n. 1, p. $63-69,2000$.

PANACHUKI, E.; ALVES SOBRINHO, T.; VITORINO, A. C. T.; CARVALHO, D. F.; URCHEI, M. A. Avaliação da infiltração de água no solo, em sistema de integração agricultura-pecuária, com uso de infiltrômetro de aspersão portátil. Acta Scientiarum Agronomy, Maringá, v. 28, n. 1, p. 129 - 137, 2006.

PEREIRA, S. B. Desprendimento e arraste do solo em decorrência do escoamento superficial. $81 \mathrm{f}$. Dissertação (Mestrado em Engenharia Agrícola) - Universidade Federal de Viçosa, Viçosa, 2000.

PRUSKI, F. F.; RODRIGUES, L. N.; SILVA, D. D. Modelo hidrológico para estimativa do escoamento superficial em áreas agrícolas. Revista Brasileira de Engenharia Agrícola e Ambiental, Campina Grande, v. 5, n. 2, p. 301 - 307, 2001.

SILVA, L. S.; GODINHO, F. V. Infiltrômetro de disco para determinação da condutividade hidráulica de solo não saturado. Ciência Agrotécnica, Lavras, v. 26, n. 3, p. 585 - 588, 2002. 
FLORESTA, Curitiba, PR, v. 41, n. 3, p. 629-640, jul./set. 2011.

Parchen, C. A. P.; Péllico Netto, S.; Rizzi, N. E. 